\title{
Effect of HX108-CS supplementation on exercise capacity and lactate accumulation after high-intensity exercise
}

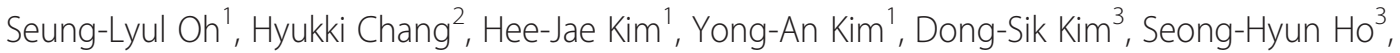
Seon-Hee $\mathrm{Kim}^{3}$ and Wook Song ${ }^{1,4^{*}}$

\begin{abstract}
Background: In the present study, we determined the effects of HX108-CS (mixed extract of Schisandra chinensis and Chaenomeles sinensis) supplementation on lactate accumulation and endurance capacity. Furthermore, we examined CK (creatine kinase), LDH (lactate dehydrogenase) activity to determine whether the HX108-CS affected markers of skeletal muscle injury in vivo and in vitro.

Methods: Exercise capacity was measured by an exhaustive swimming test using ICR mice divided into four groups; one group received distilled water (DW) (Control group, $n=10$ ), and the other groups received three different dosages of HX108-CS (10, 50 and $100 \mathrm{mg} / \mathrm{kg}, \mathrm{n}=10$ per group) solution in water orally. Then, for the time-dependent measurements of blood lactate, CK, and LDH, Sprague-Dawley rats were divided into two groups; one received DW (Control group, $\mathrm{n}=10$ ), and the other group received HX108-CS (100 mg/kg, $\mathrm{n}=10$ ) solution in the same way as mice. Before the exercise test, the animals were given either DW or HX108-CS for 2 weeks. High-intensity treadmill exercise was performed for 30 minutes. Blood samples were collected and analyzed during and after exercise. For the in vitro experiment, $\mathrm{C}_{2} \mathrm{C} 12$ cells were treated with HX108-CS to examine its effect on lactate production, CK, and LDH activity.

Results: Blood lactate concentration was significantly lowered immediately after treadmill exercise in HX108-CS group; however, there were no significant differences in activities of CK and LDH between HX108-CS and control during treadmill exercise and recovery phase. Furthermore, treatment with $100 \mathrm{mg} / \mathrm{kg}$ of HX108-CS led to a significant increase in the time to exhaustion in swimming test, and concurrently blood lactate concentration was significantly decreased in 50 and $100 \mathrm{mg} / \mathrm{kg}$ treated group. Moreover, our results of in vitro experiment showed that HX108-CS suppressed lactate production, CK, and LDH activity in a dose-dependent manner.
\end{abstract}

Conclusions: These results suggest that supplementation with HX108-CS may enhance exercise capacity by lowering lactate accumulation. This may in part be related to an amelioration of skeletal muscle injury.

Keywords: HX108-CS, Schisandra chinensis, Chaenomeles sinensis, Endurance capacity, Exercise capacity, Lactate accumulation

\footnotetext{
* Correspondence: songw3@snu.ac.kr

${ }^{1}$ Health and Exercise Science Laboratory, Institute of Sports Science, Seoul National University, 599 Gwanang-no, Gwanak-gu, Seoul 151-742, Korea

${ }^{4}$ Institute on Aging, Seoul National University, Seoul, Korea

Full list of author information is available at the end of the article
} 


\section{Background}

The important of lactate metabolism for endurance performance has recently been demonstrated. The effect of lactate production on acidosis has been the topic of recent researches in the field of exercise physiology. Robergs et al., have discussed the creation of $\mathrm{H}^{+}$ions that occurs during glycolysis and the production of lactate in circulating level causes acidosis and in turn that increased lactate production is one of the several causes of muscle fatigue during intense exercise [1]. Also, lower blood lactate concentrations at a given workload improve endurance exercise in various populations $[2,3]$.

In recent years, various strategies for improvement of endurance capacity have been adopted in an attempt to attenuate the muscle damage caused by exercise. Schisandra chinensis and Chaenomeles sinensis are usually known as medicinal plants with few side effects such as toxicity. Schisandra chinensis is a fruit of Schisandra chinensis Biollon of Schisandraceae. Several studies exist on the general composition of the extract of the Schisandra berries and pharmacological experiments have shown its anti-fatigue effects on small rodents [4]. It has also been used as a tonic for the treatment of chronic fatigue [5], for example, in Russia, it is used for anti-fatigue material [6]. On the other hand, Chaenomeles sinensis is a fruit of Chaenomeles sinensis Koehne of Rosaceae. The fruit of Chaenomeles sinensis is used in traditional medicine for the treatment of cough, common cold, and pain in Korea, Japan and China. It has been reported to contain phenolic acids, flavonoids, triterpenes, and fragrant compounds. Furthermore, it has also been known to have anti-oxidant $[7,8]$ and anti-influenza effect [9].

Several previous studies have shown that the supplementation of natural substances can decrease the contribution of exercise-induced physical fatigue and improve the animal's physiological capacities. Administration of Schisandra seed extract (SSE) extended the duration of swimming of mice [10-12]. These mice that have been treated over 2 to 4 weeks period, showed increased swimming capacity even after 24 to 48 hours cessation period. In addition, the race horses treated with Schisandra chinensis were able to complete the race at an average of 1.8 second faster and showed lower levels of lactate after exercise, indicating an improvement in the physical performance of the horses [13,14].

To the best of our knowledge, there has been no report to examine the effectiveness of Chaenomeles and Schisandra on the exercise-induced lactate production and improvement of endurance performance. Therefore, we invented HX108-CS which contains both Schisandra chinensis and Chaenomeles sinensis extracts as active ingredients for lowering lactate accumulation and for enhancing athletic capability. In the present study, we determined the effects of HX108-CS supplement on lactate accumulation during and after high-intensity treadmill exercise. Endurance capacity was also evaluated with exhaustive swimming test. Furthermore, we measured CK and LDH activities to examine whether the HX108-CS can decrease muscle injury in vivo and in vitro.

\section{Methods}

\section{Animals and surgery}

Male ICR mice (4 weeks old, $n=40)$ and Sprague-Dawley rats ( 6 weeks old, $n=20$ ) were obtained from Central Lab Animal Inc. (Seoul, Korea), kept in air-conditioned room, and acclimated for at least 7 days. The mice were divided into four groups; one group received distilled water (DW) (Control group, $\mathrm{n}=10$ ), and the other groups received three different dosages of HX108-CS (10, 50 and $100 \mathrm{mg} /$ $\mathrm{kg}, \mathrm{n}=10$ per group) solution in water orally. Then, the rats were divided into two groups; one received DW (Control group, $\mathrm{n}=10$ ), and the other group received HX108-CS $(100 \mathrm{mg} / \mathrm{kg}, \mathrm{n}=10)$ solution in the same way as mice. Before the exercise test, the animals were given either DW or HX108-CS for 2 weeks. In the rats, they were anesthetized with zoletil $50(10 \mathrm{mg} / \mathrm{kg}$, i.p.; Vibac Laboratories, Carros, France) for surgery. For the blood analysis, a silicone catheter was inserted into the jugular vein and fixed by a $35 \mathrm{~mm}$ silk thread. The exteriorized distal end of the catheter was fixed at the animal's nape as described in a previous study [15]. Three days after surgery, the rats were kept individually in their cages until the start of the running tests for full recovery. All experimental procedures were approved in accordance with the institutional animal care and use guidelines of the Animal Experimental Center at Seoul National University.

The procedures for handling and caring for the animals were performed in accordance with the NIH Guide for the Care and Use of Laboratory Animals. The experimental protocol was approved by the Institutional Animal Care and Use Committee of Laboratory Animal Resources at Seoul National University (SNU-100705-6).

\section{Preparation of HX108-CS}

Total water-soluble extract of the dried fruits, HX108-CS was prepared from these hardy kiwifruits. Briefly, the dried Schisandra chinensis and Chaenomeles sinensis fruits were mixed at a 2:1 ratio by weight and extracted by boiling in DW for 3 hours. The extract was filtered with Whatman filter paper (No. 2, $110 \mathrm{~nm}$ ), and concentrated using a rotary evaporator, followed by a freeze-drying process. Powdered HX108-CS was dissolved in DW at a concentration of $200 \mathrm{mg} / \mathrm{ml}$ and stored at $-80^{\circ} \mathrm{C}$ until use.

\section{Cell differentiation and sample treatment (in vitro)}

C2C12 cell line (kindly donated by Prof. Kang, Seoul, Korea) was routinely maintained in Dulbecco's modified Eagle's medium (DMEM) supplemented with 15\% heat 
inactivated fetal bovine serum (FBS), $100 \mathrm{IU} / \mathrm{ml}$ penicillin $\mathrm{G}$ and $100 \mu \mathrm{g} / \mathrm{ml}$ streptomycin in a humidified $5 \% \mathrm{CO}_{2}$ atmosphere at $37^{\circ} \mathrm{C}$. The medium was changed three times a week. The cells were harvested and reseeded when reached by $50 \%$.

For lactate measurement, $\mathrm{C} 2 \mathrm{C} 12$ cells were seeded on 24-well plates $\left(2.5 \times 10^{4}\right.$ cells $\left./ 500 \mu \mathrm{l}\right)$ in DMEM medium. C2C12 cells were treated with HX108-CS (250, 500 and $1000 \mu \mathrm{g} / \mathrm{ml}$ ) for $30 \mathrm{~min}$ before $\mathrm{NaN}_{3}$ (sodium azide) treatment. After $30 \mathrm{~min}, \mathrm{NaN}_{3}$ was treated to cells and incubated for 6.5 hrs. After 7 hrs, supernatant of cells was harvested and used for lactate measurement. For LDH and $\mathrm{CK}$ activities measurement, $\mathrm{C} 2 \mathrm{C} 12$ cells were differentiated for 5 days. Briefly, C2C12 cells were seeded on 6-well plates $\left(2 \times 10^{5}\right.$ cells $\left./ 2 \mathrm{ml}\right)$ in DMEM medium. To induce differentiation, the medium was replaced with DMEM containing 2\% horse serum prior to the cells reaching confluence. The medium was changed every day. Differentiated C2C12 cells were treated with HX108-CS (250, 500, and $1,000 \mu \mathrm{g} / \mathrm{ml}$ ) and 2, 4-dinitrophenyl (DNP) for $1 \mathrm{hr}$. After $1 \mathrm{hr}$, supernatant of cells was harvested and used for $\mathrm{LDH}$ and CK measurement.

\section{Swim-to-exhaustion exercise test}

Each of the mice had a weight attached (10\% body weight) to the tail for the duration of the swim-to-exhaustion exercise. The mice were assessed to be fatigued when they failed to rise to the surface of the water to breathe within $5 \mathrm{sec}$. Swimming time was recorded as minute for each mice. Blood samples were taken by capillary glass tubes from eye venous pool of mice when they were no longer able to continue to swim. Throughout the course of this experiment, one researcher who did not know the grouping of the mice determined the duration of swimming time to exhaustion. The swimming exercise was carried out in a tank $(32 \times 50 \times 35 \mathrm{~cm})$, filled with water to $25 \mathrm{~cm}$ depth and maintained at a temperature of $33 \pm 1^{\circ} \mathrm{C}$.

\section{Progressive treadmill exercise protocol}

Two hours before the experiment, the rats were fasted by removing chow to minimize the glucose effect from consumption just prior to the measurement. A week before the day of experiment, all animals were familiarized to the treadmill, starting with walking on the treadmill $(5 \mathrm{~m} / \mathrm{min})$ and then running at $15 \mathrm{~m} / \mathrm{min}, 0 \%$ grade for $20 \mathrm{~min} /$ day, 5 days/week. The day of the experiment, the rats were placed on the treadmill at $0 \%$ slope and the speed was gradually increased up to $25 \mathrm{~m} / \mathrm{min}$ for $30 \mathrm{~min}$.

\section{Measurements of lactate, LDH and CK activity}

In vitro study, lactate production, $\mathrm{LDH}$ and $\mathrm{CK}$ activity were measured using commercial kit (Lactate assay, Bioassay systems, USA; LDH assay, Takara, Japan; CK assay, Bioassay systems, USA). For lactate measurement, the working reagent (assay buffer, enzyme, NAD, PMS, MTT) was added into plate and tapped the plate to mix. After $0 \mathrm{~min}$ and $20 \mathrm{~min}$, the absorbance at $565 \mathrm{~nm}$ was read using a 96-well plate reader. For LDH assay, the reaction mixture was added into plate and incubated for $30 \mathrm{~min}$. After incubation, the absorbance at $490 \mathrm{~nm}$ was read using a 96-well plate reader. For CK assay, the plate was incubated at $37^{\circ} \mathrm{C}$ for $10 \mathrm{~min}$. After $10 \mathrm{~min}$ and $40 \mathrm{~min}$, the absorbance at $340 \mathrm{~nm}$ was read using a 96-well plate reader.

In vivo study, fatigue related parameters were evaluated as described previously [16] with some modifications. Lactate concentration (Lactate pro LT-1710, ARKRAY Inc., JAPAN) was determined from whole blood samples before, during (20 and $25 \mathrm{~min}$ ) and immediately after exercise and recovery phases $(3,6,9,15$ and $30 \mathrm{~min}$ after exercise) on the treadmill. On the other hand, LDH and CK levels were measured from whole blood samples before, immediately after exercise and recovery phases $(15$ and $30 \mathrm{~min}$ after exercise). At least $30 \mu \mathrm{l}$ of blood sample was taken from the jugular vein catheter to measure blood lactate, LDH and CK activities. Blood CK and LDH activities were assayed using commercially available kits (LDH assay, Takara, Japan; CK assay, Bioassay systems, USA).

\section{Statistical analysis}

Data were presented as mean \pm S.E.M, and differences between vales were compared with two-way repeated measure analysis of variance (ANOVA) followed by Dunnett's multiple comparisons with the pre-exercise value as a control. Differences between groups were tested with unpaired Student's t-test by using Origin 8.0. $P$ values less than 0.05 , which were calculated as one-tailed $P$ values, were considered to be statistically significant.

\section{Results}

Effect of HX108-CS on lactate concentration, CK, and LDH activity after high-intensity treadmill exercise

HX108-CS substantially affects both accumulation and removal of blood lactate levels during and after highintensity treadmill exercise (Figure 1A). The lactate levels of the resting state were not statistically different between the control rats $(1.1 \pm 0.09 \mathrm{mmol} / \mathrm{L})$ and HX108-CS treated rats $(0.98 \pm 0.10 \mathrm{mmol} / \mathrm{L})$. However, at immediately after high-intensity exercise, the maximally elevated blood lactate concentration was significantly higher in control group compared HX108-CS group $(7.4 \pm 0.62 \mathrm{mmol} / \mathrm{L}$ vs. $4.4 \pm 0.42 \mathrm{mmol} / \mathrm{L}, \mathrm{p}<0.05)$. Moreover, in early recovery phase, HX108-CS facilitated the removal of blood lactate significantly $(\mathrm{p}<0.05)$ at 3 and 6 min after treadmill exercise (Figure 1A).

As shown in Figure 1B, both the control and HX108-CS groups showed a similar pattern of changes in blood concentration of CK. In both groups, CK increased 

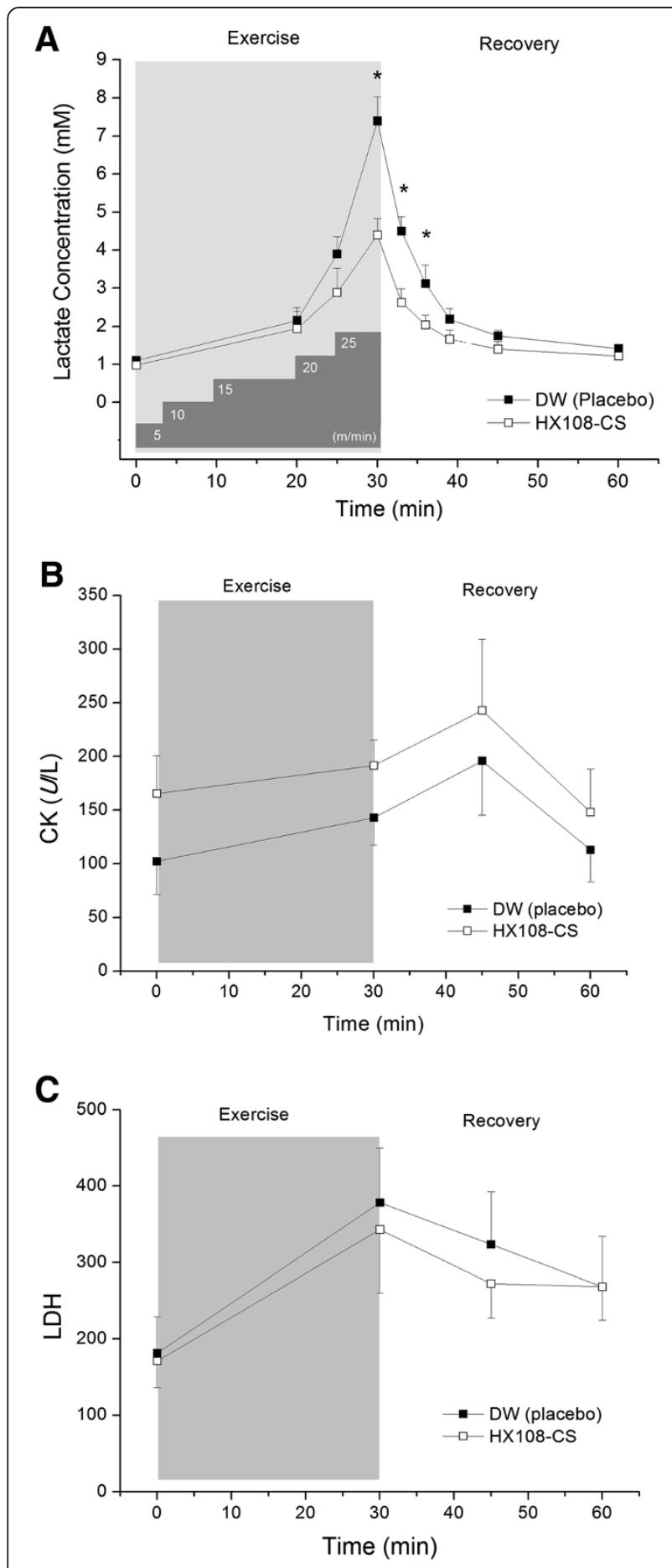

Figure 1 Effect of HX108-CS on CK, LDH and lactate after progressive treadmill exercise. Male SD rats were divided into 2 groups; DW group (DW treated, $n=7$ ), HX108-CS treated group $(100 \mathrm{mg} / \mathrm{kg}, \mathrm{n}=8)$. All of rats ran with the same increasing velocity from $5 \mathrm{~m} / \mathrm{min}$ up to $25 \mathrm{~m} / \mathrm{min}$ for 30 minutes at $0 \%$ grade (protocol was illustrated under the graph). Blood samples were collected from jugular vein before, during and after treadmill exercise. (A) Lactate concentration in blood, (B) CK activity in blood and (C) LDH activity in blood. Values are expressed as mean \pm SEM. ${ }^{*} p<0.05$ significant difference between DW group vs. HX108-CS treated group. immediately after exercise, and reached their maximum values at 15 min recovery phase, then returned to the preexercise level at 30 min recovery. On the other hand, the peak concentration of blood LDH occurred immediately after exercise in both groups then gradually decreased (Figure 1C). However, there were no significant differences in the CK and LDH between control group and HX108-CS treated group.

\section{Effect of HX108-CS on endurance capacity and blood} lactate concentration in swim-to-exhaustion exercise test We performed swim-to-exhaustion exercise test using the mice to examine the effect of HX108-CS on endurance capacity. The significant changes of endurance capacity and lactate production followed by HX108-CS supplementation were found in a dose of $100 \mathrm{mg} / \mathrm{kg}$ of HX108-CS. HX108-CS treated animals $(100 \mathrm{mg} / \mathrm{kg})$ were statistically improved the duration of swimming time to exhaustion by $24.7 \%$ compared with control group (Figure $2 \mathrm{~A}$, $\mathrm{p}<0.05$; swimming duration of $100 \mathrm{mg} / \mathrm{kg}$ and control were $13.58 \pm 0.09$ and $10.89 \pm 0.19$, respectively). Additionally, blood lactate concentration after exhaustive swimming was significantly decreased at 50 and $100 \mathrm{mg} / \mathrm{kg}$ of HX108-CS ( $<0.05$, Figure 2B). These results indicated that HX108-CS enhanced the endurance capacity with lessening accumulation of blood lactate.

\section{Effect of HX108-CS on lactate, CK, and LDH activity in C2C12 cells}

HX108-CS was treated with graded concentration $(0,250$, 500 and $1000 \mu \mathrm{g} / \mathrm{ml}$ ) in C2C12 cells to examine the effect of HX108-CS on fatigue related parameters including lactate production, CK, and LDH activity. HX108-CS suppressed lactate production, CK, and LDH activity in a dose-dependent manner. As shown in Figure 3A, inhibition of CK activity was fit to the Hill equation, giving an $\mathrm{EC}_{50}$ of $323.23 \pm 6.48 \mu \mathrm{g} / \mathrm{ml}$. Also, when HX108-CS was treated with $500 \mu \mathrm{g} / \mathrm{ml}$, HX108-CS induced inhibition of LDH activity was evaluated to $43.8 \pm 2.5 \%$ of the control value (Figure 3B). Furthermore, HX108-CS suppressed the production of lactate by $50 \%$ in a dose of $250.23 \pm 4.54 \mu \mathrm{g} / \mathrm{ml}$ (Figure 3C).

\section{Discussion}

Major findings of current study were that i) oral HX108-CS $(100 \mathrm{mg} / \mathrm{kg})$ supplement significantly lowered the blood lactate accumulation immediately after high-intensity treadmill exercise and early recovery phase; ii) HX108-CS $(100 \mathrm{mg} / \mathrm{kg})$ treated mice improved the duration of swimto- exhaustion that was concomitant with the decrease of lactate concentration; iii) HX108-CS inhibited lactate release, CK, and LDH activity in a dose-dependent manner $(250,500$, and $1,000 \mu \mathrm{g} / \mathrm{ml})$ in vitro. The present invention, named HX108-CS, relates to a composition which contains 


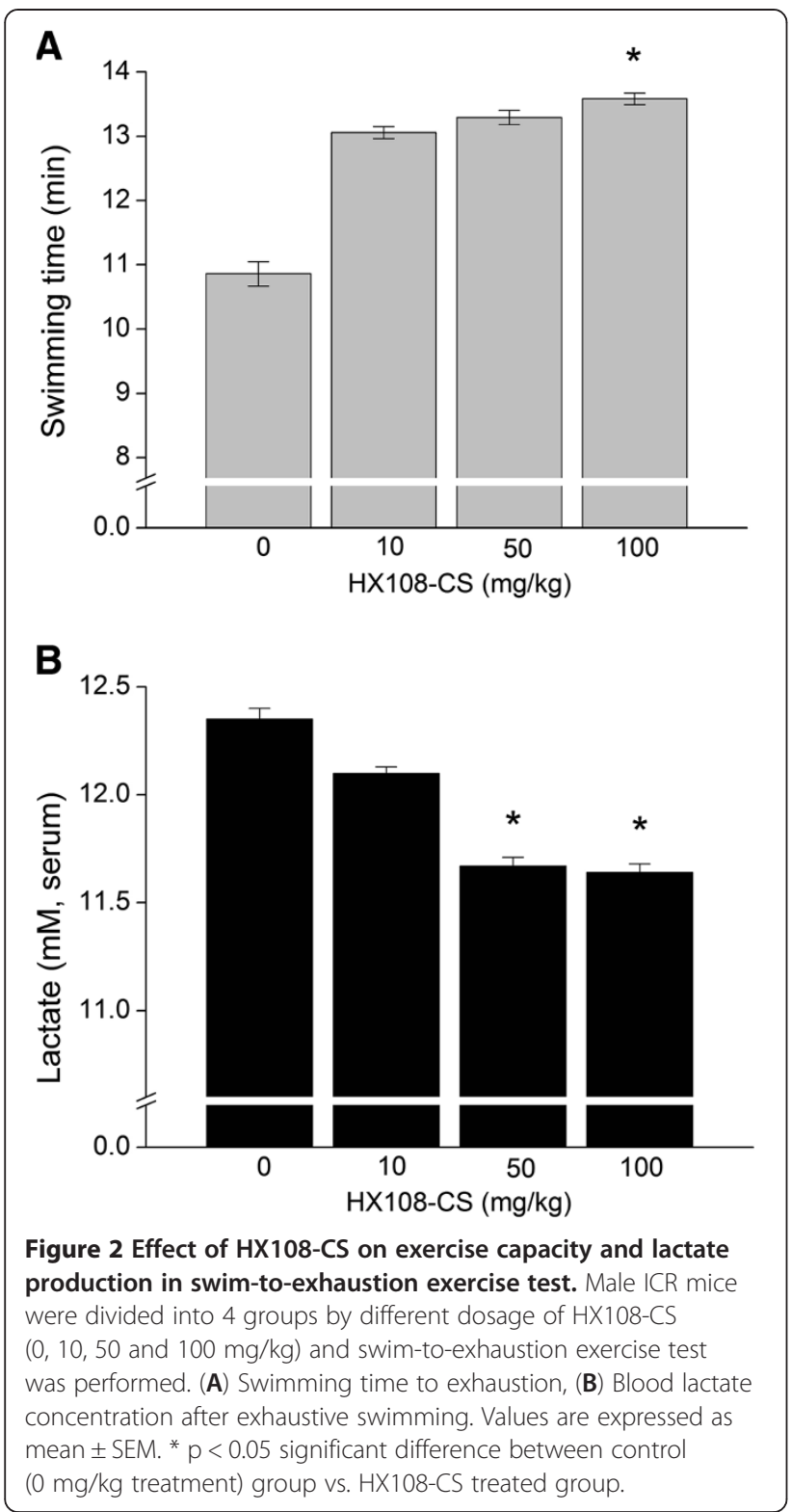

Schisandra chinensis and Chaenomeles sinensis. Schisandra chinensis extracts was reported as active ingredients for alleviating muscle fatigue [17], stress behavior [18], and enhancing exercise capability [10-14]. However, little is known about the effect of this new composition (HX108-CS) on lactate production, endurance performance, and the markers of muscle injury after high-intensity exercise.

We investigated to determine whether supplementation of HX108-CS suppresses exercise-induced elevation of lactate level, CK and LDH activities in rats (Figure 1). Our results showed that the blood lactate concentration in HX108-CS treated group was significantly lower than in the control group immediately after exhaustive exercise (Figure 1A) suggesting that lactate production

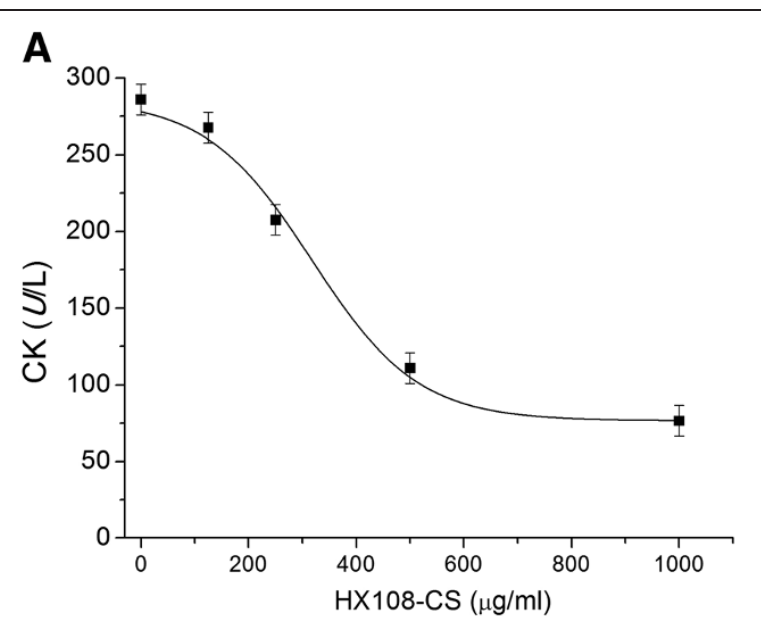

B
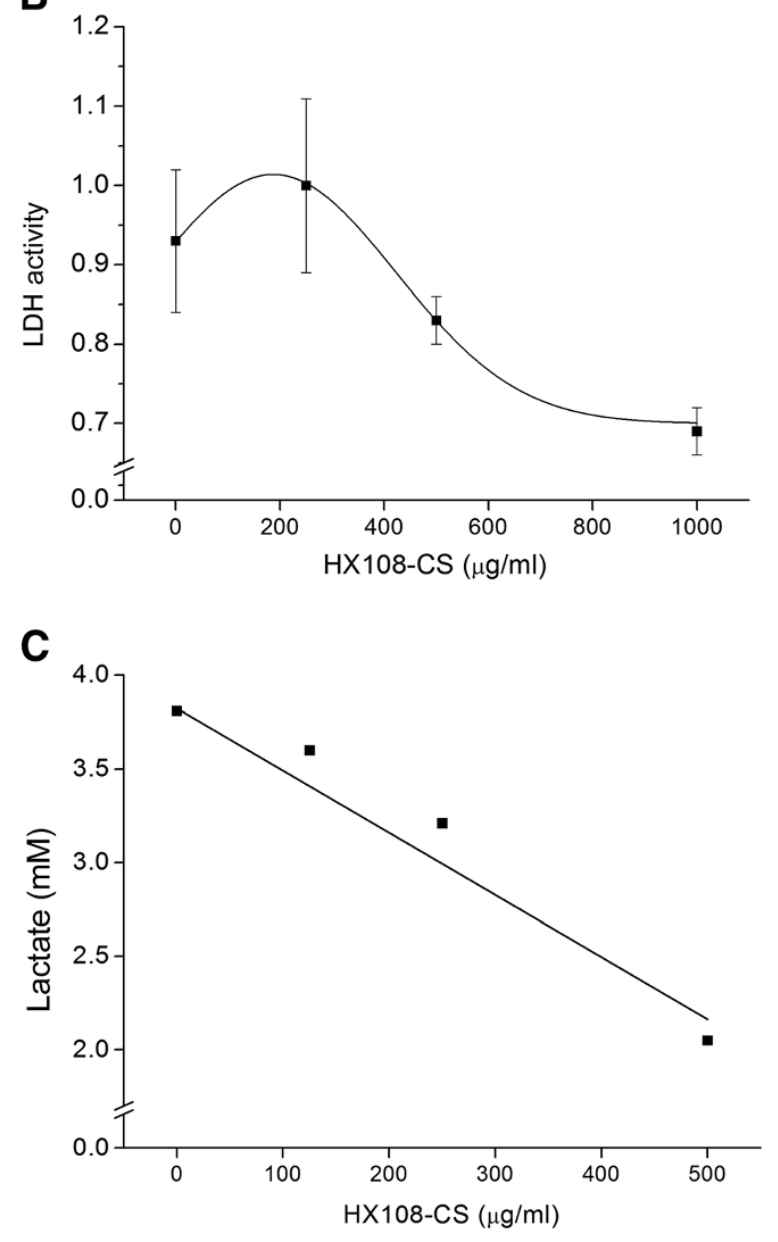

Figure 3 Effect of HX108-CS on CK, LDH and lactate in C2C12 cells. C2C12 cells were treated with HX108-CS (250, 500 and $1000 \mathrm{\mu g} / \mathrm{ml})$ and 2, 4-dinitrophenyl (DNP) and sodium azide $\left(\mathrm{NaN}_{3}\right)$ treatment for $\mathrm{CK}(\mathbf{A})$ and $\mathrm{LDH}$ activity $(\mathbf{B})$, lactate $(\mathbf{C})$ measurement respectively. Values are expressed as mean \pm SEM. 
was partially suppressed with HX108-CS supplementation compared with placebo group. Concurrently, removal of lactate during recovery period was significantly faster in HX108-CS treated group than placebo group.

On the contrary, CK and LDH activities were not significantly changed during and after exhaustive treadmill exercise and there was no statistical difference between HX108-CS and control groups. It may partly due to the dose of HX108-CS. The dose effective to elicit significant changes in vitro may not be high enough for changing in circulating levels. It would be worthwhile to try various high doses of HX108-CS for future study. In previous studies, serum CK activity has been shown to be elevated for 24 hours after exercise bouts, with a gradual return to basal levels in $72-96$ hours $[19,20]$, while serum LDH activity has been shown to be elevated 24 hours after exercise bouts and is maintained for 48-72 hours [21,22]. However, these previous studies were carried out in human subjects, and exercise intensity was also supposed to be higher than present study.

In addition, we conducted another in vivo experiment using mice to evaluate the effects of HX108-CS supplementation on endurance capacity using swimming exercise. We investigated whether or not oral supplementations of HX108-CS (0, 10, 50 and $100 \mathrm{mg} / \mathrm{kg}$ ) would extend swimming time and suppress blood lactate concentration. Our results showed that duration of swimming time was prolonged significantly only in $100 \mathrm{mg} / \mathrm{kg}$ of HX108-CS group and swimming-induced lactate concentration was inhibited by both 50 and $100 \mathrm{mg} / \mathrm{kg}$ of HX108-CS groups (Figure 2). These results indicated that supplementation of HX108-CS is likely to be related to the improvement of endurance capacity, and the most effectual dose of HX108-CS in this regard was $100 \mathrm{mg} / \mathrm{kg}$. To date, only one study reported different dose $(30 \mathrm{mg} / \mathrm{kg})$ of Schisandra chinensis had significant effect on the endurance capacity in mice with the measurement of blood lactate concentration [17]. In this study [17], the increase ratio of the blood lactate was also significantly lower in dose of $50 \mathrm{mg} / \mathrm{kg}$ of Schisandra chinensis aqueous extract consistent with the data of swimming endurance test. Possible explanations why doses were different between our study and previous study with respect to endurance capacity and lactate include (i) treatment period (14 days vs. 28 days), (ii) composition of supplement (mixed extract treatment vs. Schisandra chinensis only treatment) (iii) different species of mice (ICR vs. Kuming), (iv) exercise intensity (different weight bearing; $10 \%$ vs. $5 \%$ of body mass).

Finally, we investigated the effect of HX108-CS on lactate production, $\mathrm{CK}$, and $\mathrm{LDH}$ activity in vitro using C2C12 cells (Figure 3). HX108-CS suppressed the CK, $\mathrm{LDH}$ activity and lactate production in a dose-dependent manner in $\mathrm{C} 2 \mathrm{C} 12$ cells. Treatment of intact muscles with
2, 4-dinitrophenyl (DNP) has previously been shown to result in a decline in muscle ATP concentration [23] and increase of CK activity concentration [24]. Release of CK from skeletal muscle has long been used as an index of damage to muscle in both in vitro and in vivo studies. The CK reaction is of vital importance to skeletal muscle contraction. This reaction provides the most immediate means to replenish ATP in the cytosol. In this investigation, the DNP-induced increases of lactate production, $\mathrm{CK}$, and LDH activities were inhibited by HX108-CS treatment $(250,500$, and $1,000 \mu \mathrm{g} / \mathrm{ml})$ in $\mathrm{C} 2 \mathrm{C} 12$ cell. The results of in vitro study suggest that HX108-CS potentially exerts beneficial effects on muscle fatigue by alleviating muscle damage.

\section{Conclusions}

In conclusion, our data suggest that the composition of the present invention (HX108-CS) may have beneficial effects on endurance capacity by lowering lactate accumulation. This may in part be related to an amelioration of skeletal muscle injury. Further studies to elucidate the underlying mechanisms how HX108-CS exerts anti-fatigue effect will be required. In addition, careful consideration of clinical trial with human participants will be a subject of a follow-up study.

\section{Abbreviations \\ LDH: Lactate dehydrogenase; CK: Creatine kinase; SSE: Schisandra seed extract; DW: Distilled water.}

\section{Competing interests}

The authors' declare that they have no competing interest.

\section{Authors' contributions}

Oh, Chang, and Song were responsible for study design and interpretation of data. Oh and Kim (YA) drafted the manuscript and performed the statistical analysis. Kim (HJ) was mostly involved in acquisition of the data of this manuscript. Kim (DS), Ho, and Kim (SH) carried out in vitro experiments and provided detail methods sections. All authors read and approved the final manuscript.

\section{Acknowledgments}

This work was supported by a grant (PF03211-00) from Plant Diversity Research Center of 21st Century Frontier Research Program and partly by Bio \& Medical Technology Development Program (MEST, 2011-0030133) of the National Research Foundation funded by the Korean government.

\section{Author details}

${ }^{1}$ Health and Exercise Science Laboratory, Institute of Sports Science, Seoul National University, 599 Gwanang-no, Gwanak-gu, Seoul 151-742, Korea. ${ }^{2}$ Department of Human Movement Science, Seoul Women's University, Seoul, Korea. ${ }^{3}$ ViroMed Co., Ltd, Seoul, Korea. ${ }^{4}$ Institute on Aging, Seoul National University, Seoul, Korea.

Received: 3 January 2013 Accepted: 13 March 2013 Published: 15 April 2013

\section{References}

1. Robergs RA, Ghiasvand F, Parker D: Biochemistry of exercise-induced metabolic acidosis. Am J Phyiol Regul Integr Comp Physiol 2004, 287(3):R502-R516. 
2. Lorenzo S, Minson CT, Babb TG, Halliwell JR: Lactate threshold predicting time-trial performance: impact of heat and acclimation. J Appl Physiol 2011, 111:221-227.

3. Loukogeorgakis SP, Panagiotidou AT, Broadhead MW, Donald A, Deanfield $J E$, MacAllister RJ: Remote ischemic preconditioning provides early and late protection against endothelial ischemiareperfusion injury in humans: role of the autonomic nervous system. Am Coll Cardiol 2005, 46(3):450-456

4. Volicer L, Sramka M, Janku I, Capek R, Smetana R, Ditteova V: Some pharmacological effects of Schizandra chinensis. Arch Int Pharmacodyn 1966, 163:249-262

5. Zhang $\mathrm{CL}$, He XL: Advances in Research on Schisandra chinesis (Turcz.) Baill. J Baoding Teach Coll 2005, 17:36-39.

6. Hancke J, Burgos R, Ahumada F: Schizandra chinensis (Turcz.) Baill. Fitoterapia 1999, 70:451-471.

7. Sancheti S, Sancheti S, Bafna M, Seo SY: Antidiabetic, antihyperlipidemic, and antioxidant effects of Chaenomeles sinensis fruit extract in streptozotocin-induced diabetic rats. Eur Food Res Technol 2010, 231:415-421.

8. Zhang LX, Xu HD, Li SF: Effects of micronization on properties of Chaenomeles sinensis (Thouin) Koehne fruit powder. Innov Food Sci Emerg Technol 2009, 10:633-637.

9. Sawai R, Kuroda K, Shibata T, Gomyou R, Osawa K, Shimizu K: Anti-influenza virus activity of Chaenomeles sinensis. J Ethnopharmacol 2008, 118:108-112.

10. Lupandin AV: Schizandra chinensis effect on some parameters of the organism reactivity. In Materials on the 23rd Scientific Session of Khabarovsk Medical Institute. Khabarovsk: The Ministry of Health of RSFSR, Khabarovsk Medical Institute; 1965:151-153.

11. Lupandin AV: Lapajev II. In Schizandra. Edited by Konovalov PF. Khabarovsk: Khabarovskoye Knizhnoye Izdatelstvo; 1981:1-89.

12. Lupandin AV, Kolosova NG, Matayev RN, Ovsyanikova VY: On the adaptogenic effect of Schizandra and other adaptogens. In Edited by Brekhman II, Fruentov NK. Syktyvkar: Acute and Chronic Stress, V.L. Komarov's Far East Branch of USSR Academy of Science; 1986:86-90.

13. Ahumada F, Hermosilla J, Hola R, Pena R, Wittwer F, Wegmann E, Hancke J, Wikman G: Studies on the effect of Schizandra chinensis extract on horses submitted to exercise and maximum effort. Phytother Res 1989, 3:175-179.

14. Hancke J, Burgos R, Wikman G, Ewertz E, Ahumada F: Schizandra chinensis, a potential phytodrug for recovery of sport horses. Fitoterapia 1994, 65:113-118.

15. Chang HK, Saito T, Ohiwa N, Tateoka M, Deocaris CC, Fujikawa T, Soya H: Inhibitory effects of an orexin-2 receptor antagonist on orexin A- and stress-induced ACTH responses in conscious rats. Neurosci Res 2007, 57:462-466

16. Chang HK, Park JY, Suk MH, Lee HJ, Kang HJ, Choi KM, Song W: Comparison of lactate threshold, glucose, and insulin levels between OLETF and LETO rats after all-out exercise. J Sports Sci Med 2009, 8:381-387.

17. Cao S, Shang H, Wu W, Du J, Putheti R: Evaluation of anti-athletic fatigue acticity of Schizandra chinensis aqueous extracts in mice. African J Pharm Pharmacol 2009, 3:593-597.

18. Lee S, Kim DH, Jung JW, Oh JH, Park HJ, Park C, Huh Y, Cheong JH, Oh TH, Ryu JH: Schizandra chinensis and Scutellaria baicalensis counter stress behaviors in mice. Phytother Res 2007, 21:1187-1192.

19. Mougios V: Reference intervals for serum creatine kinase in athletes. $\mathrm{Br} \mathrm{J}$ Sports Med 2007, 41:674-678.

20. Brancaccio P, Maffulli N, Mario Limongelli F: Creatine kinase monitoring in sport medicine. Br Med Bull 2007, 81-82:209-230.

21. Bessa A, Nissenbaum M, Monteiro A, Gandra PG, Nunes LS, Bassini-Cameron A, Werneck-de-Castro JP, de Macedo DV, Cameron LC: High intensity ultraendurance promotes early release of muscle injury markers. $\mathrm{Br} J$ Sports Med 2008, 42:589-593

22. Chevion S, Moran DS, Heled Y, Shani Y, Regev G, Abbou B, Berenshtein E, Stadtman ER, Epstein Y: Plasma antioxidant status and cell injury after severe physical exercise. Proc Natl Acad Sci USA 2003, 100:5119-5123.
23. West-Jordan JA, Martin PA, Abraham RJ, Edwards RH, Jackson MJ: Energy dependence of cytosolic enzyme efflux from rat skeletal muscle. Clin Chim Acta 1990, 189:163-172.

24. Maglara AA, Vasilaki A, Jackson MJ, McArdle A: Damage to developing mouse skeletal muscle myotubes in culture: protective effect of heat shock proteins. J Physiol 2003, 548:837-846.

doi:10.1186/1550-2783-10-21

Cite this article as: Oh et al:: Effect of HX108-CS supplementation on exercise capacity and lactate accumulation after high-intensity exercise. Journal of the International Society of Sports Nutrition 2013 10:21.

\section{Submit your next manuscript to BioMed Central and take full advantage of:}

- Convenient online submission

- Thorough peer review

- No space constraints or color figure charges

- Immediate publication on acceptance

- Inclusion in PubMed, CAS, Scopus and Google Scholar

- Research which is freely available for redistribution

Submit your manuscript at www.biomedcentral.com/submit
C) BioMed Central 